\title{
Localized Skin Lesion
}

National Cancer Institute

\section{Source}

National Cancer Institute. Localized Skin Lesion. NCI Thesaurus. Code C39688.

A pathologic process that affects the skin and is confined to a specific area. 